\title{
MTHFR A1298C POLYMORPHISM AND THE VASO-OCCLUSIVE CRISS IN SICKLE CELL DISEASE
}

\author{
Ahmed A. Raiuf ${ }^{a}$, Mona M. hamdy ${ }^{b}$, Osama F. Shalaan ${ }^{c}$, Moustafa A. Sakr ${ }^{c}$, Abdel \\ Rahman A. Abdel Rahman ${ }^{c}$
}

${ }^{a}$ Clinical Biochemistry Department, National Liver Institute , Menoufia University, Egypt

b Pediatrics Department, Faculty of Medicine, Cairo University, Egypt

c Molecular Diagnostics and Therapeutics Department, Genetic Engineering and

Biotechnology Research Institute, University of Sadat City, Egypt

Corresponding author:

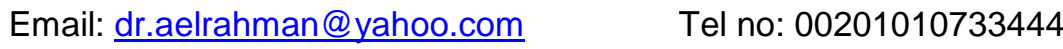

\begin{abstract}
Vaso-occlusion is the most signs and symptoms of sickle-cell anemia (SCA). Elevated Homocysteine concentration contributes to form thrombosis, a frequent event in sickle cell anemia. Methylenetetrahydrofolate reductase (MTHFR) is a key enzyme, which modifies homocysteine metabolism, and some polymorphisms of gene encoding this enzyme are accompanied with a decreased activity of the enzyme. The aim of the study was to study the association between the A1298C polymorphism and the incidence of Vaso-occlusive crisis. A case- control study was conducted over a period of one year from Jan- Dec 2014 inclusive, 50 patients were collected together with age, and sex matched healthy control 30 cases. Venous blood samples were collected from groups to estimate serum Homocysteine, folic acid and A1298C polymorphism identification through tetra primer ARMS PCR. Statistical analysis was done, using the student $t$-test, Pearson correlation analysis and $\mathrm{x} 2$ test. We found that, the homocysteine level was significantly upregulated in the patients group compared with control group with $p$ value $<0.01$. Moreover, a strong positive correlation between Homocysteine level and the frequency of Vaso-occlusive crisis was found $(x 2=4.836$ and $p$ value 0.04$)$. Association between vaso-occlusive events and polymorphism frequency showed a non-significant difference for the $A 1298 C$ gene $(x 2=1.720 ; p=0.4231)$. We conclude that Hyperhomocysteinaemia is positively correlated with the frequency of Vaso-occlusive crisis and the presence of $A 1298 \mathrm{C}$ MTHFR gene polymorphism is not a risk factor for vaso-occlusive crisis in the SCD patients.
\end{abstract}

Keywords: Vaso-occlusive crisis. Hyperhomocysteinaemia, MTHFRA1298C

\section{INTRODUCTION}

Sickle cell anemia (SCA) is a disease disorder characterized by a single mutation of the six codon of $\beta$-globin chain ( $\beta 6-G A G \rightarrow G T G)$, in which the glutamic acid was replaced by Valine. Despite this fact, the clinical course of individuals suffering from SCA is largely variable, the severity of the symptoms ranging from asymptomatic to a very severe course (Steinberg and Adewoye, 2006; Adams et al., 2003). The phenotypic variability of the SCA may be elucidated by some genetic factors, those related to $\beta$-globin genes have been wellknown (Adams et al., 2003). Many evidences suggest that, the SCA and other chronic hemolytic anemia are manifested by increased the coagulable state with promoted of thrombin and fibrin formation as well as platelet activation with an increased risk for thromboembolic complications (Ataga et al., 2003).

Homocysteine is a sulfur amino acid and involved in methionine metabolism as an 
intermediate state. In many patients with inborn errors of homocysteine metabolism, liver or kidney disease, nutrient deficiencies, homocysteine levels may rise over normal levels and cause adverse health outcomes. It was reported that the elevated plasma tHcy is an indirect cause for cardiovascular-related as well as non-cardiovascular-related deaths (Vallset et al., 2001; Van der put et al., 1998).

MTHFR gene 1298A-C polymorphism resulted in a glu429-to-ala (E429A) substitution. This polymorphism destroys the Mboll recognition site and has an allele frequency of 0.33 (Van der put et al., 1998). Whereas the 677C-T polymorphism occurs within the predicted catalytic domain of the MTHFR enzyme, the $1298 \mathrm{~A}-\mathrm{C}$ transition is located in the supposed regulatory domain. The $1298 \mathrm{~A}-\mathrm{C}$ polymorphism resulted in lowering MTHFR activity, which was more proclaimed in the homozygous than heterozygous cases (Van der put et al., 1998).

So the aim of this study to investigate whether children with sickle cell disease have elevated concentration of serum Homocysteine with diminished levels of folate. Determine the correlation between Hyperhomocysteinaemia and Vaso-occlusive crisis. Further to assess an association between the A1298C polymorphism and the frequency of Vaso-occlusive crisis.

\section{PATIENTS AND METHODS PATIENTS}

A case-control study was conducted over a period of one year from first of Jan. 2104 to the end of Dec. 2014 , 50 cases of patients (sickle cell anemia and Sickle cell - Thalassemia) were collected from the Hematology center in Abo Elresh Hospital together with 30 healthy cases, age and sex matched, were taken from Menoufia Hospital. History of renal, hepatic or cardiac disease was considered as exclusion criteria. All the individuals were subjected to the following after signing an informed consent by one of the parents or the patient himself: full history taking laying stress on age , gender, residence ,frequency of occurrence of Vasoocclusive crisis, severity of pain and site, whether they took folic acid. Vaso-occlusive crisis severity was estimated according to the pain scale (1-10) plus whether the patient uses hospital, emergency or random ambulatory care for pain relief in the previous day. Physical examination was performed. A 3cc of venous blood sample were collected from both groups and centrifuged, after centrifugation the serum were taken to the Medical Research Unit, in the Genetic Engineering and Biotechnology Research Institute (GEBRI), University of Sadat city, Menoufia, to estimate serum homocysteine and folic acid level.

\section{METHODS}

Venous blood samples were drawn from each subject in three separate test tubes: one tube was used for biochemical testing. The others were collected on EDTA for complete blood picture, haemoglobin electrophoresis and DNA extraction.

Homocysteine: All blood samples and standard solutions of Homocysteine were measured chromatographically with C-18 column. Mobile phase solution linear gradient from $0.1 \mathrm{M}$ acetate buffer $\mathrm{pH} 4$ including $2 \%$ methanol to $0.1 \mathrm{M}$ phosphate buffer including $6 \%$ methanol over $15 \mathrm{~min}(0-100 \%)$ was used for chromatographic analysis, with flow rate $0.5 \mathrm{ml} / \mathrm{min}$ and UV-VIS detection at wavelength $245 \mathrm{~nm}$.

Folic acid: Folic acid was assayed using Mybiosource ELISA kits (San Deigo, california, U.S.A) The kit used a double-antibody enzymelinked immunosorbent assay (ELISA) sandwich method to assay the level of Human Folic acid (FA) in samples.

DNA Extraction: Total genomic DNA was extracted from blood leucocytes pellets by salting out extraction method using a wizard genomic DNA extraction kit (Promega). Red blood cell was lysed by using red blood cell lysis buffer (20 mM tris-HCL pH 7.6) followed by centrifugation. Nuclei lysis was achieved by cell lysis solution containing $(10 \mathrm{mM}$ tris- $\mathrm{HCl} \mathrm{pH}$ 8.0, $1 \mathrm{mM}$ EDTA pH 8.0, 0.1\% (w/v) SDS) and proteinase $\mathrm{K} \quad(20 \mathrm{mg} / \mathrm{mL})$, and then centrifugation was done. Protein precipitation was completed by protein precipitation solution $(60 \mathrm{~mL}$ of $5 \mathrm{M}$ potassium acetate, $11.5 \mathrm{~mL}$ of glacial acetic acid, $28.5 \mathrm{~mL}$ of water). Finally isopropanol was used to precipitate the DNA and then washed by ethanol $70 \%$ and 
rehydrated in Tris EDTA buffer (10 $\mathrm{mM}$ tris, 1 $\mathrm{mM}$ EDTA $\mathrm{pH}$ 8.0) and stored at $-20 \circ \mathrm{C}$ till assayed. DNA purity and concentration were estimated by the spectrophotometer at 260 and $280 \mathrm{~nm}$ absorbance.

MTHR A1298C Genotyping: The tetra-primer PCR procedure was used to genotype methylene tetrahydrofolate reductase (MTHFR) A1298C polymorphism. The method uses four primers to generate a larger fragment from DNA containing the SNP and the products representing each of the two allelic forms. Primers can be assigned to amplify fragments of differing sizes for each allele, and the bands can be easily identified by using agarose gel electrophoresis depending on size. The specificity of the reaction, could be increase by adding a mismatch at the $3^{\prime}$ end of each of the two allele-specific primers. The primers were used as described in two studies by (Lajin et al., 2012 and Etlik et al., 2011). We utilized the 'BLAST' software

at http://www.ncbi.nlm.nih.gov/blast to check the specificity of the primers. Gradient PCR was carried out using the Biometra $T$ Professional thermal cycler (Biometra, Germany), to specify the proper annealing temperature for each primer set. The PCR reaction volume was of $20 \mu \mathrm{L}$, containing $2 X$ GoTaq ${ }^{\circledR}$ Green Master Mix (Promega, USA), genomic DNA (at a concentration of $50-100 \mathrm{ng} / \mu \mathrm{L}$ ), primers (primer sequences were as follows: The common forward primer is $5^{\prime}$ GAAGAAGTTTGCATGCTTGTGGTTG 3', common reverse primer $5^{\prime}$ CAGGCAAGTCACCTGGGAGAGA 3', for 1298A GCAAAGAACGAAGACTTCAAAGACACATT 3 and for 1298-C 5' GAGGAGCTGACCAGTGATGC $3^{\prime}$ and optimized concentrations of $0.5,0.5,1.0$ and $0.1 \mu \mathrm{M}$ respectively. The primer sets with the nearest optimal annealing temperatures were then incorporated into single mixes and gradient PCR was displayed, in try to optimize the procedures in multiplex reactions. PCR conditions were done as follow; an initial denaturation at $95{ }^{\circ} \mathrm{C}$ for $5 \mathrm{~min}$ followed by 30 cycles of (denaturation at $96{ }^{\circ} \mathrm{C}$ for $30 \mathrm{sec}$, annealing at $54 \circ \mathrm{C}$ for $30 \mathrm{sec}$, extension at $72{ }^{\circ} \mathrm{C}$ for $40 \mathrm{sec}$ ), and final extension at $72{ }^{\circ} \mathrm{C}$ for 5 min. PCR products were separated by electrophoresis on a $2 \%$ agarose gel and the image was captured by gel documentation system under UV Transilluminator. The size of the amplicons obtained as follow; 593 and 281 bp bands for wild-type homozygote, 593, 361, 281, bands for heterozygote, and 593, 361 bands for mutant homozygote (Figure 1).

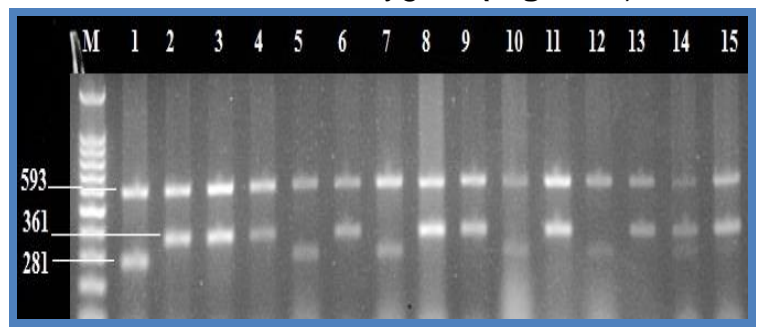

Figure (1): Agarose gel electrophoretograms showing MTHFR A1298C SNP genotyping by duplex tetraprimer ARMS PCR. The outer primers amplified a large fragment of the target gene (593 bp), irrespective of MTHFR genotype, which served as an internal control. The inner primers combined with the respective opposite outer primer to generate smaller allele-specific amplicons. M, Sizer ${ }^{\mathrm{TM}}$-100 DNA Marker (iNTRON Biotechnology, Korea). Samples no 14 and 15 showed two amplicons which denoted heterozygous state while samples no 1,5,7,10 and 12 showed one amplicon (281 bp) which denoted homozygous state, samples no 2,3,4,6,8,9,11 and 13 showed one amplicon (361 bp) which denoted mutant state.

\section{Statistical analysis}

Data were statistical analyzed using SPSS Win statistical package version 18. Numerical data were calculated as mean, range and standard deviation. Qualitative and categorical data were analyzed as frequency and percentage. Pearson correlation test was used between serum Homocysteine and Folic acid level, as well as between Homocysteine level and the frequency of Vaso-occlusive crises. $r$. value range from -1.0 to 1.0 referees and reflects the extent of a linear relationship between two data sets. P-value was calculated, a value $<0.05$ indicates statistical significance.

\section{RESULTS AND DISCUSSION}

The clinical parameters of study group are summarized in table (1). A non-significant 
difference is noted regarding age, sex, SBP, and DBP. Homocysteine level was higher in the patients group compared with control group with mean and standard deviation of $(44.68 \pm 9.096)$ while in the control group standard deviation of $(18.81 \pm 3.76)$. In addition, folic acid level was lower in the patients group compared with control group with mean and standard deviation $(12.02 \pm 2.76)$ while in the control group (14.68 $\pm 2.99) \mathrm{ng} / \mathrm{ml}$. Pearson correlation shows a negative significant correlation between
Homocysteine level and folic acid level (r. value $=-0.1, p$. value 0.04) as it is shown in (Figure 2).

The correlation between the SCD genotypes and the incidence of vaso-occlusive event was significant $(x 2=4.836 ; p=0.04)$, with the majority of the cases occurring in patients with the Hb SS genotype, as shown in table (2). Association between A1298C polymorphism and biochemical parameters of study group are summarized in table (3).

\begin{tabular}{|c|c|c|c|}
\hline Variables & $\begin{array}{l}\text { SCD }(\mathrm{N}=50) \\
\text { Mean } \pm \mathrm{SD}\end{array}$ & $\begin{array}{l}\text { Controls }(\mathrm{N}=30) \\
\text { Mean } \pm \mathrm{SD}\end{array}$ & $p$ value \\
\hline Gender & $\begin{array}{l}\text { Male: } 33(66 \%) \\
\text { Female: } 17(34 \%)\end{array}$ & $\begin{array}{l}\text { Male: } 17(60 \%) \\
\text { Female: } 13(40 \%)\end{array}$ & 0.797 \\
\hline Age (years) & $6.20 \pm 2.55$ & $6.03 \pm 2.64$ & 0.781 \\
\hline Weight (kg) & $19.28 \pm 8.01$ & $21.73 \pm 7.41$ & 0.169 \\
\hline Height (centimeters) & $103.90 \pm 15.98$ & $111.67 \pm 16.99$ & 0.079 \\
\hline Heart rate/minute & $88.42 \pm 13.92$ & $90.10 \pm 11.26$ & 0.577 \\
\hline Systolic BP & $101.74 \pm 9.50$ & $104.83 \pm 8.95$ & 0.154 \\
\hline Diastolic BP & $66.90 \pm 6.98$ & $66.17 \pm 5.97$ & 0.633 \\
\hline Haemoglobin (g/L) & $7.97 \pm 1.66$ & $10.947 \pm 1.1383$ & $<0.01$ \\
\hline MCV & $82.08 \pm 11.04$ & $75.28 \pm 4.74$ & 0.004 \\
\hline WBCs (thousands /cm) & $11.528 \pm 5.18$ & $8.64 \pm 3.43$ & 0.009 \\
\hline Platelets (thousands /cm) & $307.24 \pm 191.35$ & $295.63 \pm 76.37$ & 0.752 \\
\hline HbA (\%) & $13.89 \pm 13.33$ & $95.79 \pm 1.366$ & $<0.01$ \\
\hline HbA2 (\%) & $3.47 \pm 1.59$ & $3.473 \pm 0.80$ & 0.992 \\
\hline Homocysteine $(\mu \mathrm{mol} / \mathrm{L})$ & $44.68 \pm 9.096$ & $18.81 \pm 3.76$ & $<0.01$ \\
\hline Folic acid (ng/ml) & $12.02 \pm 2.76$ & $14.68 \pm 2.99$ & 0.002 \\
\hline
\end{tabular}

Table (1): The clinical parameters of study groups.

Where a non-significant difference is noted regarding all parameters including homocysteine and folic acid level.

Association between vaso-occlusive events and polymorphism frequency (table 3 ) showed a non-significant difference for the $\mathrm{A} 1298 \mathrm{C}$ gene $\left(x^{2}=1.720 ; p=0.4231\right)$.

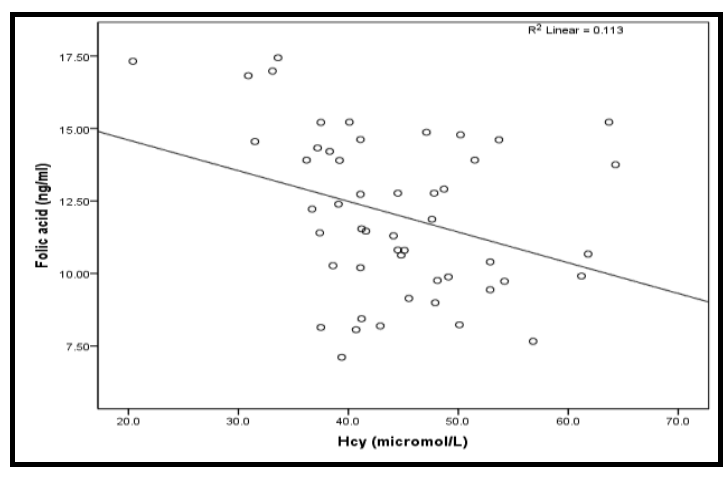

Figure (2): homocysteine \& folic acid correlations 


\begin{tabular}{|llll|} 
& $\begin{array}{c}\text { Positive } \\
\text { Crisis }\end{array}$ & $\begin{array}{c}\text { Negative } \\
\text { Crisis }\end{array}$ & Total \\
\hline SS & 12 & 6 & 18 \\
\hline S/B & 11 & 21 & 32 \\
\hline Total & 23 & 27 & 50 \\
\hline $\begin{array}{l}\text { Chi-squared: } \mathbf{4 . 8 3 6} \\
\text { Significance level: } 0 . \mathbf{0 4 0}\end{array}$ & DF: 1 & \\
\hline
\end{tabular}

Table (2): $x 2$ test between vaso-occlusive crisis and sickle genotype.

\begin{tabular}{|c|c|c|c|c|}
\hline & $\begin{array}{l}\text { AA } \\
(\mathrm{no}=17)\end{array}$ & $\begin{array}{l}\mathrm{AC} \\
(\mathrm{no}=25)\end{array}$ & $\begin{array}{l}\text { CC } \\
\text { (no=8) }\end{array}$ & p value \\
\hline \multicolumn{5}{|c|}{ Bibchemical parameters (Anova Test) } \\
\hline $\begin{array}{l}\text { Hcy } \\
(\mu \mathrm{mol} / \mathrm{L})\end{array}$ & $43.3 \pm 6.1$ & $45.1 \pm 9.0$ & $43.6 \pm 12.8$ & 0.828 \\
\hline $\begin{array}{l}\text { Folate } \\
(\mathrm{ng} / \mathrm{ml})\end{array}$ & $12.2 \pm 3.0$ & $11.7 \pm 2.6$ & $12.2 \pm 2.8$ & 0.800 \\
\hline \multicolumn{5}{|c|}{ Vaso-occlusive Crisis (Chi Square Test) Total } \\
\hline Negative & 7 & 15 & 5 & $27(54.0 \%)$ \\
\hline Positive & 10 & 10 & 3 & $23(46.0 \%)$ \\
\hline Total & $\begin{array}{l}17 \\
(34.0 \%) \\
\end{array}$ & $\begin{array}{l}25 \\
(50.0 \%)\end{array}$ & $\begin{array}{l}8 \\
(16.0 \%)\end{array}$ & 50 \\
\hline \multicolumn{5}{|c|}{ Chi-squared: 1.72 DF: 2 Significance level: 0.4231} \\
\hline
\end{tabular}

Table (3): Association between A1298C polymorphism and biochemical parameters. $X 2$ test between vaso-occlusive crisis and A1298C polymorphism.

In the present study, patients with homozygous sickle cell have a higher frequency of vasoocclusive crises than patients with sickle cell$\beta+$-thalassemia genotype .This observation was consistent with the results of other previous studies (Platt et al., 1994; Nagel et al., 1985).

In this study, we found that the mean values of homocysteine in AA genotype, AC genotype and CC genotype were not statistically significant. This result comes in accordance with (Hanson et al., 2001; Friedman et al., 1999 and Friso et al., 2003) who observed that there was no significant difference in mean homocysteine concentrations in individuals who were either heterozygous carries or homozygous for the $1298 \mathrm{C}$ allele compared with homozygous individuals for the 1298A allele. This means that the A1298C mutation may has no significant influence on plasma homocysteine levels and can be explained by the fact that the $\mathrm{A} 1298 \mathrm{C}$ polymorphism is located within the $\mathrm{C}$-terminal regulatory domain of the MTHFR gene, while the C677T mutation is located within the catalytic domain of the gene.
Moreover in this study, MTHFR A1298C allele was not associated with vaso-occlusive complications in patients with SCD. This can be explained by the absence of correlation between A1298C polymorphism and homocysteine level among sickle cell disease patients. There are a few studies were done on the A1298C MTHFR polymorphism in children with strokes, but their results are contradicted Rook et al., 2005; Biswas et al., 2009; Akar et al., 2001; Sirachainan et al., 2008; Komitopoulou et al., 2006; Morita et al., 2009). Two studies reported a positive association between A1298C polymorphism and vascular strokes. The first study was performed by (Rook et al., 2005) on the group of 21 young individuals after stroke, ethnically heterogeneous (people from 4 different ethnic populations). Such group tends to be extremely small and insufficient for an analysis of genetic polymorphisms. Additionally, the authors had no control group; so they compared the patient's results with known population controls. The second finding with positive result was made by (Biswas et al., 2009) on an AsianIndian population. The incidence of the $\mathrm{C}$ allele in the control individual was exceptionally low (.08), which could be the cause of the observed significant difference between studied patients and controls in the Biswas et al.(14) findings. The problem of each of these studies is a relatively small individual size of the study groups.

On the other hand, many studies (Akar et al., 2001; Sirachainan et al., 2008; Komitopoulou et al., 2006; Morita et al., 2009) reported that, there was no association between the A1298C polymorphism and pediatric stroke.

\section{REFERENCES}

Adams, G.T., Snieder, H., McKie, V.C., et al. (2003). Genetic risk factors for cerebrovascular disease in children with sickle cell disease: design of a case-control association study and genome wide screen. BMC Medical Genetics;4:6.

Akar, N., Akar, E., Ozel, D., et al. (2001). Common mutations at the homocysteine metabolism pathway and pediatric stroke. Thromb Res. 102:115-120. 
Ataga, K.I., and Orringer, E.P. (2003). Hypercoagulability in sickle cell disease: a curious paradox. Am J Med;115:721-728.

Biswas, A., Tiwari, A.K., Ranjan, R., et al. (2009). Prothrombotic polymorphisms, mutations, and their association with pediatric non-cardioembolic stroke in AsianIndian patients. Ann Hematol. 88:473-478.

Etlik, O., Koksa,I V., Arican-Baris, S.T., et al. (2011). Development and validation of a cost-effective in-house method, tetra-primer ARMS PCR assay, in genotyping of seven clinically important point mutations. Mol. Cell. Probes. 25(4), 177-181.

Friedman, G., Goldschmidt, N., Friedlander, Y., et al. (1999). A common mutation A1298C in human methylenetetrahydrofolate reductase gene: Association with plasma total homocysteine and folate concentrations. J Nutr. 129(9):1656-1661.

Friso, S., Girelli, D., Trabetti, E., et al. (2002). A1298C methylenetetrahydrofolate reductase mutation and coronary artery disease: relationships with $\mathrm{C} 677 \quad \mathrm{~T}$ polymorphism and homocysteine/folate metabolism. Clin Exp Med. 2(1):7-12.

Hanson, N.Q., Aras, 0., Yang, F., et al. (2001). C677T and A1298C polymorphism of the methylenetetrahydrofolate reductase gene. Incidence and effect of combined genotypes on plasma fasting and post-methionine load homocysteine in vascular disease. Clin Chem. 47(4): 661-666

Komitopoulou, A., Platokouki, H., Kapsimali, Z., et al. (2006). Mutations and polymorphisms in genes affecting hemostasis proteins and homocysteine metabolism in children with arterial ischemic stroke. Cerebrovasc Dis. 22:13-20.

Lajin, B., Alachkar, A. and Sakur, A.A. (2012). Triplex tetra-primer ARMS-PCR method for the simultaneous detection of MTHFR c.677C $>$ T and c.1298A $>C$, and MTRR c. $66 \mathrm{~A}>\mathrm{G}$ polymorphisms of the folatehomocysteine metabolic pathway. Mol. Cell. Probes. 26(1), 16-20.

Morita, D.C., Donaldson, A., Butterfield, R., et al. (2009). Methylenetetrahydrofolate reductase gene polymorphism and childhood stroke. Pediatric Neurology. 41: 247-249.

Nagel, R.L., Fabry, M.E., and Pagnier, J. (1985). Hematologically and genetically distinct forms of sickle cell anemia in Africa. The Senegal type and the Benin type. N Engl J Med. 312:880.

Platt, O.S., Brambilla, D.J., and Rosse, W.F. (1994). Mortality in sickle cell disease. Life expectancy and risk factors for early death. N Engl J Med. 330:1639.

Rook, J.L., Nugent, D.J., and Young, G. (2005). Pediatric stroke and methylenetetrahydrofolate reductase polymorphisms: an examination of C677T and A1298C mutations. J Pediatr Hematol Oncol. 27:590-593.

Sirachainan, N., Sasanakul, W., Visudtibhan, A., et al. (2008). The effect of polymorphisms of MTHFR C677T, A1298C, MS A2756G and CBS 844ins68bp on plasma total homocysteine level and the risk of ischemic stroke in Thai children. Thromb Res.122:33-37.

Steinberg, M.H. and Adewoye, A.H. (2006). Modifier genes and sickle cell anemia. Curr Opin Hematol.13:131-136.

van der Put, J., Gabreels, F., Stevens, B., et al. (1998). A second mutation in the methylenetetrahydrofolate reductase gene: an additional risk factor for neural-tube defects? Am. J. Hum. Genet. 62:1044-1051.

Vollset, S.E., Refsum H., Tverdal, A., et al. (2001). Plasma total homocysteine and cardiovascular and noncardiovascular mortality: the Hordaland Homocysteine Study. Am J Clin Nutr. 74(1):130-136. 